\title{
The JOURNAL of GLOBAL HEALTH
}

\section{Ebola and the Evolving Ethics of Quarantine}

\author{
Daniel Hughes ${ }^{1}$ \\ ${ }^{1}$ Department of Biology, Hunter College of the City University of New York, New York City, NY 10010, USA
}

\begin{abstract}
Within the context of the history of quarantine, both worldwide and in the United States, this essay analyzes current quarantine policies related to Ebola with an inquiry into both related bio-ethical concerns and an analysis of the ways in which emerging Ebola pharmaceutical treatments, particularly the rVSV-ZEBOV vaccine, may shift quarantine policies. By way of background, the historical roots of quarantine are first briefly examined alongside an analysis of why quarantine policies were not instituted in relationship to the HIV/AIDS pandemic. Then, current quarantine policies and procedures in both the developed and developing world are delineated, with an analysis of the application of these quarantine policies to Ebola. An overview is provided of how new treatment protocols may change Ebola quarantine alongside related bio-ethical concerns.
\end{abstract}

Key Words Ebola, EBOV, Quarantine, HIV, AIDS, HIV/AIDS, Liberia, Sierra Leone, Guinea, Hickox, Typhoid Mary, Merck, rVSV-ZEBOV, Congo

\section{INTRODUCTION}

The emergence of Ebola, particularly during the West African epidemic that began in 2013 and in the current outbreak of the disease in the Congo, has presented an unprecedented challenge to underresourced health care systems in some of the world's poorest countries. One public health measure dating back to ancient times that has been introduced to combat Ebola is quarantine. Quarantine measures have been deployed both in the African locus of endemic Ebola infection and in the context surrounding the handful of cases that have reached the developed world in the United States, Spain and other nations. This essay analyzes quarantine and its history with an eye toward a better understanding of how and when quarantine can or should be deployed against Ebola. A wide historical lens is appropriate given that the debates over Ebola quarantine engage with both the developing and developed world's public health systems and represent a distinct historical moment with both similarities and differences from prior epidemics of infectious diseases. Some health experts argue that as a result of the new VSV-ZEBOV vaccine and other vaccines under development, the characteristics and timeline of Ebola virus infection and updated research on the efficacy of quarantine in the contemporary world, historical quarantine practices may not always be relevant or ethical in the context of Ebola.

Quarantine for infectious disease has been part of the human response to epidemic outbreaks of communicable diseases for more than two millennia. The word "quarantine" itself is a linguistic derivative of quaranta giorni which means "40 days" in the late medieval Venetian Italian dialect. ${ }^{\text {T }}$ To protect the community on land, 40 days comprised the period during which ships had to lay at anchor in the harbor of Venetian Ragusa (now Dubrovnik, Croatia) to ensure that the sailors onboard were not infected with bubonic plague, one of three types of plague caused by the bacterium Yersinia pestis. ${ }^{2}$ Long before the etymology of the word quarantine, however, the ancient world employed quarantine procedures. The Old Testament of the Bible, for instance, refers to separation from the community for persons infected

(C) 2019 DANIEL HUGHES. This is an open access article distributed under the terms of the Creative Commons Attribution License (CC-BY 4.0), which permits the user to copy, distribute, and transmit the work provided that the original author(s) and source are credited.

Send correspondence to: daniel.hughes83@myhunter.cuny.edu 
with leprosy, an infection of the nerves, eyes, skin and nasal mucosa caused by slow-growing Mycobacterium leprae bacteria. ${ }^{3}$ Quarantine has persisted as a public health intervention from ancient times until today.

This essay defines "quarantine" as a state, period or place of isolation in which people or animals that have arrived from elsewhere or been exposed to infectious or contagious disease are placed. There are two main types of quarantine: (1) "Local elimination" refers to quarantine wherein a person who is infected or believed to be infected with a pathogen is removed from the community. A common contemporary example would be prohibiting a patient with tuberculosis from living among the general population. (2) "Defensive quarantine" refers to sealing off access to a community from abroad to stop a pathogen from entering the community. The above-described attempt to stop sailors from entering medieval Ragusa until 40 days had passed was an example of defensive quarantine.

This essay will first briefly review a few salient points in the history of American quarantine and then turn its focus to a consideration of quarantine in the context of Ebola Virus Disease ("Ebola") and related bioethical concerns. Instances of specific Ebola quarantine policies or decisions will be examined from a bioethical framework. Overall, changes to Ebola quarantine policies that are likely to emerge from the recent development by Merck of a highly effective vaccine against Ebola will be considered.

\section{BRIEF HISTORY OF AMERICAN QUARANTINE}

Ebola quarantine measures taken to halt any potential spread in the United States have engaged the public in a vigorous debate with both advocates and opponents of quarantine presenting seemingly scientific arguments and similar terminology to support their positions. ${ }^{4}$ Turmoil regarding quarantine measures and acts of defiance have had a robust history from the early days of the British colonial presence in North America. In 1663, the British authorities drew up the first plans for quarantine of ships with sailors suspected of having plague or other communicable diseases. ${ }^{5}$ In the 1730 s, New York built a quarantine station on Bedloe's Island, now Liberty Island where the Statue of Liberty stands. ${ }^{6}$ The new republic of the United States also saw the founding of multiple quarantine stations including the Philadelphia Lazaretto built in $1799 .^{7}$

One historical instance of an American local elimination quarantine that made its way into popular legend concerns Mary Mallon (1869-1938), an Irish-American immigrant cook and laundress who came to be called "Typhoid Mary" by the American press and public. ${ }^{8}$ Mallon had emigrated from Ireland around 1883-84 and subsequently worked in New York City and surrounding suburbs as a cook for wealthy families. ${ }^{9}$ Numerous family members fell sick, and in rare cases even died, after eating food Mallon had prepared. As a result, Mallon was quarantined from 1907 to 1910 on North Brother Island, located between the Bronx and Rikers Island. She was released upon explicit instruction not to return to work as a cook; a job as a laundress was instead procured on her behalf by the New York City health authorities. Work as a laundress paid less, however, and she changed her name to "Mary Brown" and returned to employment as a cook. In 1915, bacteria from Mallon caused another typhoid outbreak at Sloane Hospital for Women in New York City; this time, two women died. Mallon was then quarantined for the rest of her life (1915 to 1938) on North Brother Island at Riverside Hospital.

Mallon was an asymptomatic carrier of Salmonella typhi, known now to be the cause of the disease known colloquially as typhoid, which likely was retained in her macrophages. After her death, an autopsy found typhoid bacteria resident in her gall bladder. During her lifetime, Mallon was offered an operation to remove her gall bladder and thereby likely render her no longer infectious to others. She refused the operation. Mallon was almost certainly afraid and likely somewhat ignorant concerning the germ theory of disease or related infectious disease concepts despite efforts by the New York City health authorities to educate her concerning these topics. While a tragic figure, she was also a reasonable candidate for a local elimination quarantine. However, Mallon was highly noncompliant. She refused to regularly wash her hands or cease working as a cook, even after having obtained a job as a laundress. Additionally, Mallon refused to have her gall bladder removed as a preventative measure. A credible case can be made that due to Mallon's behavior, by which she repeatedly put others at risk of severe illness which resulted in death on several occasions, a local elimination quarantine was a measure needed to protect community welfare. Additionally, her status as an asymptomatic carrier of typhoid was rare, although other cases have been identified over the years. Accordingly, a quarantine was not wide-ranging or hard to enforce, as in Mallon's case, it implicated only one individual.

During Mallon's second and final quarantine, the 1918 to 1920 epidemic of Spanish Influenza, known today to have been caused by the H1N1 virus, brought about wide-ranging new quarantine procedures in an international landscape scarred and transformed by the conclusion of World War I. During this 
epidemic, one starkly dichotomous set of H1N1 quarantine policies involved the Samoan islands. In 1914 at the outbreak of World War I, the British seized the western Samoan islands from Germany and appointed a governor from New Zealand to the territory. ${ }^{10}$ The governor of the western Samoan islands (later the independent nation-state of "Western Samoa," which then changed its name to simply "Samoa") failed to put a defensive quarantine in place and as a result, the death rate from H1N1 on these islands exceeded 20\% of the population. In contrast, in the nearby American-controlled island of American Samoa, a complete defensive quarantine was implemented during the same era by Governor John Martin Poyer and no deaths were attributable to the Spanish influenza epidemic. The epidemic tragedy in the western Samoan islands, contrasted with the success of a defensive quarantine in American Samoa, illustrates that a defensive quarantine can be successful when it is enforceable and backed by enough resources. An isolated island in the South Pacific is perhaps inherently more favorable for a defensive quarantine, as compared with an area of land on a large land mass or otherwise closely interconnected with other terrestrial areas. Tragically, today Samoa finds itself with a devastating and entirely preventable epidemic of juvenile measles, almost exactly 100 years after the Spanish Influenza epidemic decimated the island. ${ }^{11}$

In the late 20th century, HIV/AIDS was a culturally defining infectious disease that permanently influenced ideas of when quarantine is appropriate. HIV is caused by a retrovirus that targets the immune system, particularly CD4 T cells. ${ }^{12}$ Without HAART (Highly Active Anti-Retroviral Treatment), HIV eventually progresses to AIDS, defined as a CD4 T cell count below 200/mL or the presence of an AIDS-defining disease like Kaposi's Sarcoma. For most immunocompromised patients without treatment, a suppressed immune system eventually leads to death due to secondary infection. Like Ebola, HIV can be transmitted via blood, semen, vaginal secretions and breast milk. Ebola is easier to transmit than HIV, however, given that Ebola is found in infectious quantities in additional human secretions, including urine and feces.

In the early days of the HIV/AIDS pandemic, some commentators and members of the public called for a quarantine. A December 1985 poll suggested most Americans would have supported a quarantine of HIV-positive individuals. ${ }^{13}$ Despite these views in the early days of the HIV/AIDS crisis, however, very few acts of quarantine occurred in the United States for HIV/AIDS, although intentional transmission of the virus was sometimes prosecuted under the criminal law. ${ }^{14}$ As of 1992, ten instances of HIV/AIDS quarantine have been reported in the United States, almost all of which involved relatively brief periods of isolation. Even in this era before protease inhibitors (available to U.S. HIV/AIDS patients beginning 1995) and HAART rendered HIV/AIDS a chronic if manageable lifelong illness, HIV prevention efforts focused on education, counseling, voluntary testing and partner notification, drug abuse treatment and needle exchange programs; this was the case despite HIV/AIDS having represented a fatal diagnosis on a routine basis. Reflecting these sympathetic trends, support for overt acts of stigma against persons with HIV/AIDS declined throughout the 1990s. In a 1991 poll, 34.4\% of American respondents had supported a quarantine of those with HIV/AIDS in 1991, while by 1999, the percentage supporting such a measure had dropped to $12.0 \% .^{15}$

One reason why HIV/AIDS was rarely subjected to quarantine is that, as a non-airborne illness unlike tuberculosis, behavioral means - including vaginal or anal sexual intercourse, intravenous drug usage and blood transfusions - are required to spread HIV. Additionally, the long latent period of HIV infection (frequently lasting 8-10 years) and the widespread geographical distribution of cases among a large population of infected individuals suggested that quarantine was unlikely to be a successful measure in combating the spread of the disease. Moreover, in the context of HIV/AIDS, the civil liberties of people with HIV/AIDS were seen as an important factor that factored against quarantine and needed to be weighed heavily against any alleged potential public health benefit of quarantine. Thus, the HIV/AIDS pandemic illustrated a reluctance to use quarantine in the contemporary world unless absolutely necessary, given that such a measure would radically compromise the personal autonomy and freedom of movement of those quarantined. Today, the advent of HAART treatment means that HIV-infected persons can, in most instances, obtain undetectable levels of viral particles within their blood and thereby become incapable of transmitting the virus while under active treatment, obviating any need or justification for quarantine.

In contrast to HIV/AIDS, tuberculosis, an airborne illness, continues to be quarantined on a regular basis in the United States. The legal authorization in the United States for quarantine action proceeds via 42 U.S.C. \$264, which provides the Surgeon General, under the authority of the Secretary of Health and Human Services, with peacetime authority (wartime authority is conveyed via 42 U.S.C. 8266 ) the right to enact quarantine and other measures to stop the movement of infectious disease transmission both into and within the United States. To carry out this mission, the Center for Disease Control has a 
subdivision of Global Migration and Quarantine that operates quarantine stations at approximately twenty ports of entry into the United States. Executive orders from the President authorize the specific communicable diseases for which quarantine is authorized, like cholera, diphtheria, tuberculosis, plague, smallpox, yellow fever, viral hemorrhagic fevers (including those caused by the Ebola virus, Marburg virus, and others), severe acute respiratory syndromes and influenza. A focus on contemporary Ebola quarantines both within the United States and in Africa is in order.

\section{EBOLA VIRUS DISEASE}

The first known outbreak of Ebola occurred in 1976 in Zaire (now the Democratic Republic of the Congo) and Sudan (in the region that is now South Sudan). ${ }^{16}$ The virus received its name from the Ebola River, located near the village in Congo where the 1976 outbreak was first detected. ${ }^{17}$ At first, scientists conjectured that the outbreaks must have occurred due to a single human individual who traveled between these two locations, which are located approximately 850 kilometers apart. However, it was later established that the 1976 outbreaks represented two different strains of the virus: Zaire ebolavirus and Sudan ebolavirus..$^{18}$ Ebolavirus is further subdivided into an additional two species with virulence against human hosts: Tai Forest ebolavirus and Bundibugyo ebolavirus. A fifth ebolavirus, namely Reston ebolavirus, only infects non-human primates. ${ }^{19}$

Subsequent genetic research determined that while the first reported outbreaks of the disease had occurred in 1976, the Ebola virus (EBOV) had likely evolved many years previously. Researchers had suspected that Ebola had a zoonotic origin. ${ }^{20}$ Testing of primates, however, revealed that while chimpanzees and gorillas do contract Ebola, they are dead-end hosts who are infected only once EBOV has emerged from another reservoir. ${ }^{21}$ Instead, the primary reservoir for EBOV is comprised of multiple species of fruit bats who live across a vast tropical region of equatorial Africa, stretching across the middle of the continent. ${ }^{22}$ Ebola cases have been concentrated in the equatorial African continent with a handful of Ebola cases that have emerged in the West.

EBOV, a non-segmented, negative strand RNA virus, belongs to the family Filoviridae. ${ }^{23} \mathrm{EBOV}$ infects hosts via cellular attachment molecules, including lectin-type. The only virally expressed protein on the virion surface is the EBOV glycoprotein which is crucial for attachment to the host cell and membrane fusion catalysis. The EBOV glycoprotein is thus an important vaccine target and is the molecular target for the recently developed, highly effective Merck rVSV-ZEBOV vaccine against Ebola discussed subsequently. ${ }^{24}$ EBOV particles intrude into host cells via pinocytosis. Primary viral transcription occurs in the cytoplasm followed by secondary transcription and genome replication in inclusion bodies. EBOV progeny viral particles are exported out of the cell via new viral genomes that travel to the cell surface in the form of nucleocapsids and are packaged with plasma membrane.

An Ebola epidemic among humans begins via a "spillover event" wherein a person encounters an infected animal, usually a fruit bat or a non-human primate. Ebola can then spread as a community-based infection from person-to-person. ${ }^{25}$ Methods of transmission include any direct contact via mucous membranes, broken skin or similar, with bodily fluids, encompassing blood, breast milk, semen, urine, saliva and feces. Additionally, the semen of a man who has recovered from Ebola commonly retains viral particles for an extended period after his recovery.

The symptoms of Ebola include otherwise inexplicable hemorrhaging, fever, vomiting, diarrhea, headache, muscle pain and fatigue. Symptoms appear from two to 21 days after viral exposure. The WHO estimates the historical death rate from Ebola to be approximately $50 \%$. Case fatality rates, however, have ranged from $25 \%$ to $90 \%$ in past outbreaks, due to a range of factors, including the quality of medical care that was provided to Ebola sufferers and the virulence of the Ebola strain. ${ }^{26}$

\section{BIOETHICAL CONSIDERATIONS \& FRAMEWORK FOR EBOLA QUARANTINE}

A host of difficult-to-answer bioethical questions emerge when an Ebola quarantine action is considered, whether in Africa, where the disease is endemic, or in the context of the handful of cases in the West. The 2013 to 2016 Ebola outbreak in West Africa, centered in Guinea, Sierra Leona and Liberia, had nearly 30,000 Ebola victims leading to over 10,000 deaths and thereby framed many of these difficult quarantine-related questions in vivid detail. One of the fundamental questions that must be answered in the affirmative for any Ebola quarantine to be justified is, "Will the quarantine be effective?" In the Biblical world or late medieval Venetian Ragusa, there were no vaccines and few other effective public 
health actions. Therefore, quarantine may have been a more understandable measure under a wider variety of circumstances. Today, considering the lessons of the HIV/AIDS pandemic, increased attention must be given to the importance of civil liberties weighed against the utilitarian aims of quarantine. Additionally, some commentators argue that significant attention should also be paid to the potentially economically deleterious effects of quarantine. An economic consideration of the advisability of quarantine is not a new factor to consider. In the early 19th century, British commentators militated against cholera quarantines given the deleterious effect that such actions could have had on trade.

Ross Upshur has proposed a four-prong test where each factor should be met in order to justify a public health intervention that is autonomy-limiting, such as quarantine. First, there should be the threat of an immediate harm to human life if the spread of the disease from human-to-human is not halted. Secondly, the least-restrictive means of stopping infections should be used. Third, reciprocity with those potentially quarantined is a necessity, meaning that if individuals are being asked to restrict their liberty on a public health basis, then those same individuals should be provided access to fully adequate medical care. Fourth, transparency and clear communication should be observed in all dealings with the public and with any quarantined individuals. ${ }^{27}$

Accordingly, if a quarantine action is imposed for Ebola, it should be certain that it is imposed on a rigorously scientific basis related to the likelihood of preventing new infections and with a careful consideration of the resources available to enforce the quarantine limitations. The Kaci Hickox case, discussed below in detail, is a 2014 case of quarantine of a returning American health care worker, where the basis of quarantine seems to have been largely political rather than scientific. ${ }^{28}$ The effect of such quarantines on the likelihood of health care workers serving developing world communities afflicted by Ebola should also be considered, particularly given the extreme disparities in healthcare available for Ebola based on the widely divergent quality of national health systems. ${ }^{29}$ Additionally, when quarantine is imposed in the developing world, it should be made certain that its burdens do not fall disproportionately on those who are already poor, and that the basic sustenance needs of those under quarantine should be provided for by the appropriate authorities. ${ }^{30}$

\section{RECENT EBOLA QUARANTINE DEVELOPMENTS \& QUANDARIES}

An examination of two Ebola quarantine events from 2014, during the height of the deadly 2013 to 2016 West African Ebola outbreak, will now be discussed with attention to both the historical examples and bioethical considerations discussed previously. These events, namely (1) a defensive quarantine with an attempt at a complete closure of the borders of Sierra Leone in September 2014 and (2) an alleged local elimination quarantine in October 2014 of American nurse Kaci Hickox returning to the United States from West Africa on an Ebola mission in Sierra Leone with Doctors Without Borders, illustrate some of the pitfalls of contemporary Ebola quarantines.

At the height of the 2013 to 2016 West African Ebola outbreak, a 72-hour total lockdown of the nation of Sierra Leone, with a population of approximately eight million people, was attempted in 2014 from September 19 to $21 .{ }^{31}$ During this time, approximately 28,500 health care workers and community volunteers combed the cities and countryside looking for Ebola cases and instituting small scale quarantines. These actions by the government of Sierra Leone followed a series of measures in the two preceding months of July and August across not just Sierra Leone, but also the neighboring countries of Liberia and Guinea, and the nearby nation of Nigeria, in which measures that included curfews, closing of public spaces, and travel restrictions were implemented in a desperate attempt to both identify those who had contracted Ebola and offer them health care, and to halt the spread of the disease among the wider population..$^{32}$ For instance, in the Liberian slum of West Point, soldiers attempted to enforce a quarantine of around 70,000 people over a ten-day period with limited success. Unfortunately, the September 2014 Sierra Leone nationwide quarantine, alongside these similar actions in nearby nations, was also unsuccessful, and Ebola continued to spread unabated in Sierra Leone and throughout the neighboring region of West Africa. In some instances, health care workers spread misinformation, whether knowingly or otherwise, breaking trust with communities and leading to suspicion of health care workers. Quarantines were often broken, in many instances by people who were not being provided sufficient food, and thereby had few other options than to break quarantine. More generally, Sierra Leone faced a resource scarcity paradox: if there was not enough money for a well-functioning health care system, how could there be enough resources to effectively enforce a nationwide quarantine? Furthermore, Sierra Leone was at the opposite end of the spectrum from American Samoa one hundred years earlier during the 1918 to 1920 Spanish Influenza outbreak, both in terms of Sierra Leone's geography and ability to carry out quarantine enforcement. While American Samoa was an isolated island 
where the United States' navy could be used to enforce quarantine, Sierra Leone had porous borders with Guinea and Liberia and a legacy of civil war and unrest that had led to a minimally functional national government, now attempting to enforce a nationwide quarantine that would have required a highly functioning political and military apparatus for success.

Nurse Kaci Hickox, serving with Doctors Without Borders in Sierra Leone in 2014, returned to the United States in October 2014. Arriving at Newark Airport, she was placed in quarantine under regulations that had been put into place by the state of New Jersey; other states had followed suit to enact restrictions on those returning from medical volunteering in the West African Ebola outbreak. After being held in New Jersey under quarantine and having tested negative twice for Ebola via polymerasechain-reaction (PCR) testing (which meant that she was almost certainly not a symptomatic carrier who could transmit Ebola), she was released and sent in an SUV caravan to her home in Maine, where she was still required to follow isolation protocols. She broke this protocol by going for a bicycle ride near her home and subsequently sued New Jersey, settling in 2017 for a "Bill of Rights" to be provided to quarantine patients. ${ }^{33}$ The terms of quarantine that Hickox challenged had been put into place in 2014 by New Jersey Governor Chris Christie and New York Governor Andrew Cuomo and required all health care workers returning from Liberia, Sierra Leone and Guinea be placed under a 21-day isolation protocol, as a form of local elimination quarantine. ${ }^{34}$ This protocol, which exceeded World Health Organization guidelines, was put into place following the New York City quarantine in October 2014 of Dr. Craig Spencer who had returned from West Africa infected with Ebola. One commentator termed the 2014 biomedical and cultural reaction in the United States demanding excessive quarantine as "Fearbola" rather than a scientifically informed reaction to the epidemic of a communicable disease. ${ }^{35}$ In a related vein, the new quarantine regulations enacted by New York and New Jersey (and similar regulations enacted by other states at the time) were criticized by medical authorities as "unscientific at best, and politically self-serving at worst."

This biomedical critique of the 21-day quarantine policy stems from the established observation, based on field study in West Africa, that only symptomatic Ebola sufferers who have a very high viral load in the bloodstream can transmit the virus. Accordingly, an asymptomatic returning health care worker from West Africa would not be contagious even if infected with Ebola. Moreover, fever precedes the contagious stage of Ebola. While the blood PCR test for Ebola is not always reliably positive at the precise outset of an Ebola-related fever, the PCR test is reliable after 2 to 3 days. Thus, a more scientific protocol that balances the civil liberties of returning health care workers with a need to protect the public from Ebola infection, would call for all returning Ebola health care workers to rigorously and frequently test themselves for fever and then undergo immediate PCR testing for Ebola on frequent subsequent intervals if they were found to be febrile. Such a protocol would not place unneeded 21-day movement restrictions on the handful of health care workers seeking to provide medical aid under conditions of dire need yet would also protect the public from contamination from anyone in the infectious stage of Ebola.

In 2014, the United States-based Centers for Disease Control explicitly rejected the idea of universal quarantine for returning Ebola health care workers. Instead, the CDC protocol divides travelers returning from countries with an active Ebola outbreak into four categories: high risk, some risk, low risk or no identifiable risk. The "high risk" group would include a health care worker, such as Craig Spencer or Kaci Hickox, who had actively been working with patients infected with Ebola. For high risk individuals, CDC guidelines mandate direct active monitoring for 21 days from last potential viral exposure, daily visits by a public health officer to check body temperature and monitor any other potential symptoms and avoidance of public transport and public areas where they may come in close contact with others. ${ }^{36}$

\section{DIRECTIONS FOR THE FUTURE \& CONCLUSION}

A gamechanger for future Ebola quarantine actions, and the more general treatment of the disease itself, is Merck's rVSV-ZEBOV vaccine, licensed under a compassionate use protocol and now established to be "highly effective." 37 This vaccine is part of a wider class of pharmaceutical interventions, including several additional vaccine candidates in testing, recently targeted at Ebola. ${ }^{38}$ Merck's rVSVZEBOV is a replication, recombinant-competent, vesicular stomatitis virus-based vaccine that has been genetically engineered to target the glycoprotein of the Zaire ebolavirus, crucial for entering the cell as discussed above. The rVSV-ZEBOV vaccine is being distributed widely in the current outbreak of Ebola in the Democratic Republic of the Congo in a ring protocol where the contacts of an infected person, and then the contacts of those contacts, are vaccinated. From August 2018 to March 2019, health officials mapped out 679 rings around 776 of the 951 confirmed or probable Ebola cases, thereby vaccinating 
nearly 94,000 people with Merck's rVSV-ZEBOV vaccine. ${ }^{39}$ While utilizing the rVSV-ZEBOV vaccine in the Democratic Republic of the Congo has presented many logistical challenges, given the nation's poor infrastructure and legacy of civil war, the World Health Organization and other global health bodies have saved countless lives with the rVSV-ZEBOV vaccine. Vaccination of health care providers and eventual wider availability of the rVSV-ZEBOV vaccine beyond the ring protocols has the potential to upend the status quo regarding any need for Ebola quarantine.

Ebola has brought unimaginable suffering to many thousands of people who live across one of the poorest regions of the globe. It seems cruel to draw any easy lessons from the fate of the victims of this often-fatal hemorrhagic fever. Nonetheless, it is useful and instructive to examine what we have learned thus far from the Ebola epidemic, placed within the context of the HIV/AIDS pandemic and those of other infectious diseases, regarding quarantine and its advisability and limitations. Firstly, we should acknowledge that the days of the Black Death are long past; we are not in an earlier era when both public health interventions and medical treatments were rudimentary at best and so quarantine could be widely justified. Today, our first question with quarantine must be, "Is it likely to work?" If not, then the use of quarantine cannot be justified. Secondly, with each quarantine action, we must keep in mind the civil liberties of the individuals involved, balanced against the necessity of protecting the surrounding community from pathogens. Thirdly, we must ensure that the sometimes-harsh requirements of quarantine are not borne disproportionately by the neediest citizens in the world's poorest regions; starving people are unlikely to be compliant with quarantine measures and may develop a lasting distrust of both civil and medical authorities. Fourthly, we must act collaboratively with local communities to build trust so that lasting faith in medical providers can be built, particularly in locales hard hit by infectious diseases. Lastly, we must recognize that while communicable disease outbreaks today can be volatile and unexpected, the treatments for infectious diseases are also developing rapidly. For instance, HIV/AIDS has been transformed in less than a generation from a nearly universally fatal illness to a treatable, chronic condition. There is hope that the rVSV-ZEBOV vaccine and perhaps other medical interventions against Ebola will eventually obviate the need for most quarantine actions against this disease, thus better protecting the economic liberty, freedom of movement and association and social and cultural rights of the afflicted.

\section{REFERENCES MAKE SURE ARE SUPERSCRIPT FOR IN-TEXT}

1. Koch, T. (2015). Ebola, Quarantine, and the Scale of Ethics. Disaster Medicine and Public Health Preparedness, October 2015. DOI: $10.1017 / \mathrm{dmp} .2015 .115$

2. Centers for Disease Control and Prevention. (2018). History of Quarantine. Retrieved from https://www.cdc.gov/quarantine/historyquarantine.html

3. Mackowiak, P., Sehdev, P. (2002). Origin of Quarantine. Clinical Infectious Diseases. Volume 35, Issue 9, 1 November 2002, 1071-1072. Link: https://academic.oup.com/cid/article/35/9/1071/330421

4. Gesser-Edelsburg, A. \& Shir-Raz, Y. (2015). Science vs. fear: the Ebola quarantine debate as a case study that reveals how the public perceives risk. Journal of Risk Research. Volume 20, 2017. Issue 5, 611-633. Published online: 05 Nov, 2015 doi.org/10.1080/13669877.2015.1100659

5. Tognotti, E. (2013). Lessons from the History of Quarantine, from Plague to Influenza A. Emerg Infect Dis. 2013 Feb; 19(2): 254-259. Retrieved from https://www.ncbi.nlm.nih.gov/pmc/articles/PMC3559034/

6. LaFrance, A. (2014). The Quarantine Next Door. The Atlantic Monthly (Aug. 2, 2014). Retrieved from https://www.theatlantic.com/health/archive/2014/08/the-quarantine-next-door/375465/

7. Health in the City of Philadelphia. (2018). Subsection regarding "Contagious Diseases Control." Retrieved from https://web.archive.org/web/20080508033044/http://www.phila.gov/Health/ Commissioner/History/ContagiousDiseaseControl.html

8. American Journal of Public Health (Unattributed Author). (1939). Mary Mallon (Typhoid Mary). American Journal of Public Health (Jan., 1939). Retrieved from https://aiph.aphapublications.org/doi/10.2105/AJPH.29.1.66

9. Marineli, F., Tsoucalas, G., Karamanou, M. \& Androutsos, G. (2013). Mary Mallon (1869-1938) and the history of typhoid fever. Annals of Gastroenterology 2013; 26(2): 132-134. Retrieved from https://www.ncbi.nlm.nih.gov/pmc/articles/PMC3959940/pdf/AnnGastroenterol-26-132.pdf

10. McLeod, M., Baker, M., Wilson, N., Kelly, H., Kiedrzynski, T., \& Kool J. (2008). Protective Effect of Maritime Quarantine in South Pacific Jurisdictions, 1918-19 Influenza Pandemic. Emerg Infect Dis. 2008 Mar; 14(3): 468-470. Retrieved from https://www.ncbi.nlm.nih.gov/pmc/articles/PMC2570822/

11. Kwai, I. (2019). 'Why My Baby?’: How Measles Robbed Samoa of Its Young. The New York Times. Dec. 19, 2019.

12. World Health Organization. (2019). HIV/AIDS. Retrieved from https://www.who.int/gho/hiv/en/

13. Poll Indicates Majority Favor Quarantine for AIDS Victims. (Dec. 20,1985). Byline unattributed. New York Times. Link: https://www.nytimes.com/1985/12/20/us/poll-indicates-majority-favor-quarantine-for-aids-victims.html 
14. Bayer, R. et al. (1993). AIDS and the limits of control: public health orders, quarantine, and recalcitrant behavior." $A m J$ Public Health. Oct. 1993, Vol. 83, No. 10, 1471-1476. Retrieved from https://www.ncbi.nlm.nih.gov/pmc/articles/PMC1694834/pdf/amiph00534-0105.pdf

15. Herek, G., et al. HIV-Related Stigma and Knowledge in the United States: Prevalence and Trends, 1991-1999. Am J Public Health. 2002 March; 92(3): 371-377. doi: 10.2105/ajph.92.3.371

16. Centers for Disease Control and Prevention. (2018). Ebola (Ebola Virus Disease). Retrieved from https://www.cdc.gov/vhf/ebola/index.html

17. Gonzalez, J., et al. (2018). Revisiting Ebola, a quiet river in the heart of Africa. Med Sante Trop. 2018 Feb 1;28(1):12-17. doi: 10.1684/mst.2018.0751.

18. Baseler L., Chertow, D., Johnson, K., Feldmann,H., and Morens, D. (2017). The Pathogenesis of Ebola Virus Disease. Annu. Rev. Pathol. Mech. Dis. 12, 387-418.

19. The Center for Food Security \& Public Health. (2016). Ebolavirus and Marburgvirus Infections. Retrieved from http://www.cfsph.iastate.edu/Factsheets/pdfs/viral_hemorrhagic_fever_filovirus.pdf

20. Saéz, A., et al. (2015). Investigating the zoonotic origin of the West African Ebola epidemic. EMBO Mol Med. 2015 Jan; 7(1): 17-23. doi: 10.15252/emmm.201404792

21. Centers for Disease Control and Prevention. (2018). History of Ebola Virus Disease. Retrieved from https://www.cdc.gov/vhf/ebola/history/summaries.html.

22. Baylor College of Medicine. (2019). Ebola Virus. Retrieved from https://www.bcm.edu/departments/molecularvirology-and-microbiology/emerging-infections-and-biodefense/ebola-virus

23. Lee, J. \& Saphire, E. (2009). Ebolavirus glycoprotein structure and mechanism of entry. Future Virol. 2009; 4(6): 621-635. doi: $10.2217 /$ fvl.09.56

24. Hackett, D. (2018). DRC Ebola Outbreak Has Three Big Challenges. Precision Vaccinations. May 13th, 2018. Retrieved from https://www.precisionvaccinations.com/successfully-deploying-merck $\% \mathrm{E} 2 \% 80 \% 99 \mathrm{~s}$-ebola-vaccine-rvsv-zebovrequires-leadership-logistics-and

25. Kiskowski, M. \& Chowell, G. (2016). Modeling household and community transmission of Ebola virus disease: Epidemic growth, spatial dynamics and insights for epidemic control. Virulence. 2016;7(2):163-73. doi: 10.1080/21505594.2015.1076613.

26. World Health Organization. (2018). Ebola Virus Disease. Retrieved from http://www.who.int/news-room/factsheets/detail/ebola-virus-disease

27. Upshur, R. (2003). The Ethics of Quarantine. Virtual Mentor. 2003;5(11):393-395. Retrieved from https://journalofethics.ama-assn.org/article/ethics-quarantine/2003-11.

28. Thompson, A. (2016). Bioethics meets Ebola: exploring the moral landscape. British Medical Bulletin, 117:5-13. Retrieved from https://academic.oup.com/bmb/article/117/1/5/1744475

29. Drazen, J., et al. (2014). Ebola and Quarantine. New England Journal of Medicine 2014; 371:2029-2030. DOI: 10.1056/NEJMe1413139. Retrieved from https://www.nejm.org/doi/full/10.1056/nejme1413139

30. Folayan, M., et al. (2016). Critical role of ethics in clinical management and public health response to the West Africa Ebola epidemic. Risk Management and Healthcare Policy. Volume 2016: 9, 55-65. Retrieved from https://www.dovepress.com/critical-role-of-ethics-in-clinical-management-and-public-health-respo-peer-reviewedfulltext-article-RMHP

31. Eba, P. (2014). Ebola and human rights in West Africa. The Lancet. Vol 384 Dec. 13, 2014. Retrieved from https://www.thelancet.com/action/showPdf?pii=S0140-6736\%2814\%2961412-4

32. Calain, P. \& Poncin, M. (2015). Reaching out to Ebola victims: Coercion, persuasion or an appeal for self-sacrifice? Social Science \& Medicine 147, 126-133. Retrieved from https://ac.els-cdn.com/S0277953615302021/1-s2.0S0277953615302021-main.pdf? tid $=$ c05b41f2-92c6-4759-9f61-

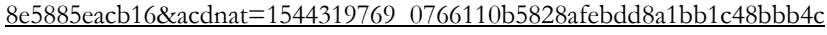

33. Santora, M. (2017). New Jersey Accepts Rights for People in Quarantine to End Ebola Suit. New York. Times. July 27, 2017. Retrieved from https://www.nytimes.com/2017/07/27/nyregion/new-jersey-accepts-rights-for-people-inquarantine-to-end-ebola-suit.html

34. Hartocollis, A. and Fitzsimmons, E. (2014). Tested Negative for Ebola, Nurse Criticizes Her Quarantine. New York Times. Oct. 25, 2014. Retrieved from https://www.nytimes.com/2014/10/26/nyregion/nurse-in-newark-tests-negative-forebola.html

35. Cao, P. (2015). "The Ethics, Politics, and Science of Ebola Quarantines." Harvard Health Policy Review. Published September 1, 2015. Retrieved from http://www.hhpronline.org/articles/2016/11/12/the-ethics-science-and-politics-ofebola-quarantines

36. McCarthy, M. (2014). CDC rejects mandatory quarantine for travelers arriving from Ebola stricken nations. BMJ: British Medical Journal Vol. 349 (27 Oct 2014 - 02 Nov 2014). Retrieved from https://www.jstor.org/stable/26518430

37. Linnane, C. (2018). Merck's experimental and unlicensed Ebola vaccine is being used in latest outbreak. MarketWatch: May 23, 2018. Retrieved from https://www.marketwatch.com/story/mercks-experimental-ebola-vaccine-isbeing-used-in-latest-outbreak-2018-05-22

38. Maxmen, A. (2018). Experimental Ebola drugs face tough test. Nature. Volume 561, Sept. 6, 2018.

39. Mole, B. (2019). As Ebola outbreak rages, vaccine is $97.5 \%$ effective, protecting over 90k people. Ars Technica. April 16, 2019. Retrieved from https://arstechnica.com/science/2019/04/ebola-vaccine-is-97-5-effective-early-outbreak-datasuggests/ 